\section{Brain, Behavior and Evolution}

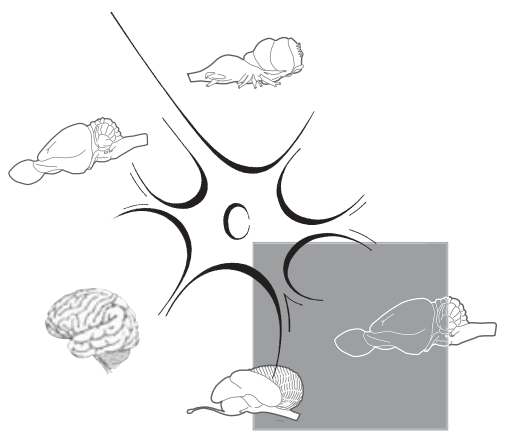

The recent paper by Wang et al. [2010] is noteworthy in that it constitutes the first detailed anatomical evidence bearing on an influential proposal made by Karten over 40 years ago [Karten, 1969; Karten and Shimizu, 1989; Karten, 1991; Shimizu and Karten, 1991; Karten, 1997] regarding the organization and phylogeny of the avian telencephalon. In essence, that proposal suggested that large parts of the avian pallial telencephalon, namely the sagittal elevation (Wulst) and the dorsal ventricular ridge (DVR), are made up of collections of what are apparently non-laminated clusters of neurons that, nevertheless, correspond in their function and connections with identifiable populations of neocortical neurons in mammals; the defining characteristics of neocortex, of course, being the presence of six neuronal layers possessing a radial organization of functional columns, dependent on their specific interlaminar connectivity. Birds and reptiles do not possess a neocortex in this sense, i.e. nowhere in the sauropsid pallium is there evidence of a hexalaminated structure comparable with the neocortex of mammals, although the Wulst and some parts of the DVR are clearly layered in the sense that there are stacked bands of neurons (although considerably wider than neocortical layers) having characteristic size, morphology, packing density and gene expression, for example, and are separated from each other by narrower, fi-

\title{
Neocortical-Like Organization of Avian Auditory 'Cortex'
}

\author{
Commentary on Wang Y, Brzozowska-Prechtl A, Karten HJ (2010): \\ Laminar and Columnar Auditory Cortex in Avian Brain. \\ Proc Natl Acad Sci USA 107:12676-12681
}

\author{
J. Martin Wild Nils O.E. Krützfeldt \\ Department of Anatomy with Radiology, Faculty of Medical and Health Sciences, \\ University of Auckland, Auckland, New Zealand
}

brous bands. In addition, some of these 'layers' in the avian Wulst and anterior DVR can be subdivided into narrower bands of cells that receive sensory-specific thalamic afferents. We emphasize this latter point because it was Karten's pioneering work on the telencephalic projections of specific auditory and visual thalamic nuclei [Karten, 1968; Karten and Hodos, 1970] that underlies the data presented by Wang et al. [2010] on the layering and interlaminar connectivity of the auditory field L complex and associated structures in chicks. Some of this layering in the field L complex in chicks had already been noted and functionally explored electrophysiologically and with 2-deoxyglucose in the 1980s and 1990s [Scheich, 1983; Heil and Scheich, 1985, 1991, 1992], with the important finding being that frequency-specific bands of activity could be demonstrated perpendicular to and across all the layers of the auditory nidopallium and adjacent mesopallium. Anatomical tracing studies in guinea fowl and pigeon defined some of the interconnections between the thalamorecipient layer of the field L complex (L2) and the adjacent layers L1 and L3, with further connections to and from the caudomedial mesopallium (CM) and projections to the dorsal nidopallium [Bonke et al., 1979; Wild et al., 1993]. Further morphological and tracing studies extended these findings to define a complicated set of auditory interconnections in a vocal- learning species dependent on auditory feedback [zebra finch: Vates et al., 1996]. Thus, considerable evidence has accumulated over the past 40 years (a) that field L in birds receives a specific, direct, tonotopically inverted projection from the nucleus ovoidalis $(\mathrm{Ov})$ of the dorsal thalamus; (b) that the major recipient of the Ov projection is a specific, small-celled layer of field L called L2; (c) that L2 projects to the adjacent laminae L1 and L 3 and receives input from the overlying caudomedial mesopallium $(\mathrm{CM})$; (d) that there are reciprocal connections of L1 and L3 with CM and with other parts of the mesopallium and arcopallium, as defined variably in different species, and (e) that frequency-specific bands extend perpendicular to and across all the field $\mathrm{L}$ and adjacent mesopallial laminae.

Two crucial points to note in this summary of the organization of the avian auditory nido- and mesopallium are (a) that $\mathrm{Ov}$ is not simply homologous to the medial geniculate body (MG) of mammals, but specifically and only to the ventral nucleus of MG (MGv), which receives its ascending auditory inputs from the central nucleus of the inferior colliculus [Karten, 1967, 1968], and (b) that the Ov-recipient part of the field L complex is not homologous to auditory neocortex, but only to neurons in the MGv-recipient layer of auditory neocortex, namely layer IV.

\section{KARGER}

Fax +4161306 1234 E-Mail karger@karger.ch www.karger.com
(C) 2010 S. Karger AG, Basel

0006-8977/10/0762-0089\$26.00/0

Accessible online at:

www.karger.com/bbe
J. Martin Wild

Department of Anatomy with Radiology

Faculty of Medical and Health Sciences, University of Auckland

Auckland 92019 (New Zealand)

Tel. +649923 6054, Fax +649373 7484, E-Mail jm.wild@ auckland.ac.nz 
The first point is important because projection targets of $\mathrm{MG}$ also include the amygdala [LeDoux et al., 1985, 1990], and parts of the mammalian amygdala are considered homologous to parts of the avian arcopallium. These facts have been used to bolster a competing hypothesis of the evolution of the avian pallium, namely the Claustroamygdalar Hypothesis, which, in contrast to the Neocortex Hypothesis [Butler et al., 2010, publication in preparation], regards the avian DVR as exclusively homologous to thalamorecipient parts of the mammalian pallial amygdala [Bruce and Neary, 1995; Bruce, 2006] and/or the endopiriform nucleus and claustrum $[\mathrm{Pu}-$ elles, 2001; Medina et al., 2004; Striedter, 2005; Abellaán et al., 2009]. But the avian Ov does not project to the arcopallium [Wild et al., 1993], and the part of the mammalian MG that projects to the amygdala is the medial or magnocellular nucleus of the MG, and not the ventral nucleus (MGv) that targets auditory neocortex [LeDoux et al., 1985, 1990].

The second point is crucial in light of Karten's hypothesis of 'cellular homology' or cortical equivalent neurons, i.e. that specific groups of neurons in the sauropsid DVR are homologous not to regions or areas of mammalian cortex but to neurons making up specific layers of neocortex. This hypothesis implies that, in addition to there being a postulated thalamorecipient lamina IV-like group of neurons in sensory regions of the avian DVR (visual and somatosensory as well as auditory), there are (or may be) groups of neurons equivalent to (homologous with) neurons making up other layers of neocortex, e.g. laminae II and III, with which the layer IV-like group of neurons are connected. Hence L1 and CM may be compared in some way with layers I-III of the mammalian neocortex [Wang et al., 2010: fig. 4]. However, groups of neurons considered equivalent to those in lamina $\mathrm{V}$ and VI of mammalian neocortex, which have projections to extratelencephalic targets, are found neither adjacent to, nor in the same part of the pallium as, the sensory thalamorecipient layer (i.e. they are not found in the anterior DVR), but rather in the arcopallium [Zeier and Karten, 1971]. Interestingly, this is not the case for the other major part of the avian dorsal pallium, the Wulst, where neurons with extratelencephalic targets lie within a layer that is adjacent to the thalamorecipient layer, as in mammalian neocortex, although in birds these two layers are not strictly separate [Wild, 1987; Wild and Williams, 2000].

To return to the work of Wang et al. [2010], it becomes clear that what was missing from previous attempts to compare the avian and mammalian auditory cortices was the demonstration of a columnar organization perpendicular to the layers, with interlaminar connections mediating the flow of information within (rather than between) columns to provide for functional units, such as define the auditory and other sensory neocortices of mammals. Wang et al. [2010] have now provided the best evidence so far of such a columnar organization in the avian brain by (a) identifying sublaminae of the previously defined layers (of L1 and CM, for instance); (b) demonstrating the morphology of specific cell classes within layers (e.g. the small granule cells of L2) and different cell types between layers, and (c) by making small extracellular injections of tracer into individual layers combined with intracellular injections, all in brain slices, to identify interlaminar connections, cell morphology, and dendritic and axonal processes.

Wang et al. [2010] summarize their findings by saying, 'Radially oriented intrinsic connections suggest that the functional unit of the avian field L/CM complex is composed not of individual nuclei, but rather of columnar modules with interconnections across laminated layers' [p 12680], and 'These findings indicate that laminar and columnar properties of the neocortex are not unique to mammals and may have evolved from cells and circuits found in more ancient vertebrates' [p 12676]. Since birds may be considered modern flying reptiles, substantiation of their latter assertion entails performing similar experiments in the brains of other reptiles, e.g. crocodiles, lizards or turtles. Because these creatures have sensory thalamic projections to their DVR that are similar to those here outlined for the DVR of birds, there may be hope of finding similar columnar and laminar organizations of sensory-specific regions in the DVR of these reptiles as well.

It may also be expected that what has been found in the field L/CM complex of chicks by Wang et al. [2010] may be found in other sensory regions of the avian DVR, e.g. the visual entopallium. This structure, which has been likened to layer IV the of mammalian extrastriate neocortex [Shi- mizu and Karten, 1991], contains at least two structural divisions that can be defined on the basis of a variety of criteria, including differential afferent and efferent projections [Benowitz and Karten, 1976; Husband and Shimizu, 1999; Krützfeldt and Wild, 2004, 2005]. On further investigation it may turn out that these two divisions of the entopallium actually contain additional subdivisions, thereby increasing the resemblance to a laminar-type organization - a resemblance that is accentuated by the presence of a narrow perientopallial belt that flanks the external division (layer?) of the entopallium. Moreover, the various types of entopallial neurons may be interconnected in a way that resembles intracortical connections in their interlaminar specificity, as postulated by Wang et al. [2010] for the chick field L/CM complex. A similar comparison can be made for the organization of the trigeminal somatosensory complex comprising the nucleus basorostralis and adjacent nidopallium [Veenman and Gottschaldt, 1986; Dubbeldam and Visser, 1987].

Whether the evidence of a laminated and columnar auditory cortex in birds presented by Wang et al. [2010] will persuade the reader that the Neocortex Hypothesis is now preferable to the Claustroamygdalar Hypothesis, with respect to the provenance and structure of the avian telencephalon, remains to be seen. The issues are extremely complex and it behooves the reader to weigh the evidence for himself or herself [Striedter, 2005; Butler et al., in press]. Also, there are still problems with the Neocortex Hypothesis that have not been resolved. The absence of lamina Vand VI-like neurons from the postulated laminae and columns proposed by Wang et al. [2010] has been noted above, and it remains a curious fact that nowhere in the avian anterior DVR are there any neurons that project out of the telencephalon (at least, none have thus far been found). Therefore, for any auditory or other sensory column to pass on whatever information is processed within the column to an extratelencephalic target, it must first make contact with the arcopallium, either directly, e.g. from L1 and L3, or indirectly, e.g. via the dorsal nidopallium [Wild et al., 1993; Vates et al., 1996]. (But whether this sequence of information flow must necessarily hold is now questionable - see below.) Karten has long suggested that large groups of neurons in certain specific parts of the intermediate arcopallium are ho- 
mologous with those in laminae V and VI of mammalian neocortex, because they have descending projections to the thalamus, optic tectum, brainstem and (upper) spinal cord that closely resemble those in mammals [Zeier and Karten, 1971; Wild et al., 1993; Dubbeldam et al., 1997; Mello et al., 1998].

However, the neocortical equivalent neuron hypothesis originally promulgated by Karten for the sensory-specific regions of the avian anterior DVR never explicitly considered another large population of mammalian neocortical neurons, namely those in lamina $\mathrm{V}$ that send their projections from all regions of the cerebral cortex to subpallial targets within the telencephalon, namely the striatum [McGeorge and Faull, 1989]. Previously, projections from sensory-specific regions of the avian DVR to the striatum were thought not to exist [Veenman et al., 1995], but this has proven to be incorrect [Dubbeldam and Visser,
1987; Vates et al., 1996; Alpar and Tömböl, 2000; Krützfeldt and Wild, 2004, 2005; unpubl. observations]. Such 'cortico-striate' neurons do not figure in the laminar schema of Wang et al. [2010] and their presence challenges the idea that neurons in field L 2 or the entopallium in birds correspond only to lamina IV neurons of auditory or extrastriate visual cortex, respectively, because although lamina IV of mammalian neocortex may contain more than one kind of neuron, none of them is known to project to the striatum. Thus, the specific, single lamina form of the cortical equivalent neuron idea was/is too simple. None of the three sensory fields - field L2, entopallium or basorostralis - can any longer be considered equivalent only to lamina IV-like neurons of the mammalian neocortices of respective auditory, visual and trigeminal somatosensory systems, for they each possess populations of neurons that project to the striatum, in addi- tion to the mesopallium and other intratelencephalic targets previously described [Wild et al., 1985; Dubbeldam and Visser, 1987; Husband and Shimizu, 1999; Alpar and Tömböl, 2000; Krützfeldt and Wild, 2004, 2005]. The projections to the striatum, of course, ensure that the sensory-specific regions of the DVR have access to a source of extratelencephalic outflow in addition to that from the arcopallium.

It is clear, therefore, that the laminae and interlaminar circuitry within the sensory-specific regions of the avian anterior DVR do not correspond exactly to those in mammalian neocortex, and perhaps that should not surprise us. Nevertheless, the unraveling of the anatomical details, as shown by Wang et al. [2010], is a prerequisite both to a better understanding of sensory processing in the avian brain and to a more informed comparison of avian and mammalian telencephala within an evolutionary context.

\section{References}

-Abellaán A, Legaz I, Vernier B, Reétaux S, Medina L (2009): Olfactory and amygdalar structures of the chicken ventral pallium based on the combinatorial expression patterns of LIM and other developmental regulatory genes. J Comp Neurol 516:166-186.

-Alpar A, Tömböl T (2000): Efferent projections from the ectostriatal core. An anterograde tracer study. Anat Anz 182:101-110.

- Benowitz LI, Karten HJ (1976): Organization of the tectofugal visual pathway in the pigeon: a retrograde transport study. J Comp Neurol 167:503-520.

Bonke BA, Bonke D, Scheich H (1979): Connectivity of the auditory forebrain nuclei in the guinea fowl (Numida meleagris). Cell Tissue Res 200:101-121.

Bruce LL (2006): Evolution of the reptilian brain; in Kaas JH (ed): Evolution of Nervous Systems, vol 2: Non-Mammalian Vertebrates. Oxford, Academic Press, pp 125-156.

Bruce LL, Neary TJ (1995): The limbic system of tetrapods: a comparative analysis of cortical and amygdalar populations. Brain Behav Evol 46:224-234.

Butler AB, Reiner A, Karten HJ (2010): Evolution of the amniote pallium and the origins of mammalian neocortex. New Studies of Neurobehavioral Evolution (a conference held in Honor of Dr Wally Welker), Washington, June 25-28.

Dubbeldam JL, Visser AM (1987): The organization of the basalis-neostriatum complex of the mallard (Anas platyrhynchos L.) and its connections with the archistriatum and the paleostriatum complex. Neuroscience 21: 487-517.
Dubbeldam JL, den Boer-Visser AM, Bout RG (1997): Organization and efferent connections of the archistriatum of the mallard, Anas platyrhynchos L: an anterograde and retrograde tracing study. J Comp Neurol 388: 632-657.

Heil P, Scheich H (1985): Quantitative analysis and two-dimensional reconstruction of the tonotopic organization of the auditory field in the chick from 2-deoxyglucose data. Exp Brain Res 58:532-543.

Heil P, Scheich H (1991): Functional organization of the avian auditory cortex analogue. I. Topographic representation of isointensity bandwidth. Brain Res 539:110-120.

Heil P, Scheich H (1992): Spatial representation of frequency-modulated signals in the tonotopically organized auditory cortex analogue of the chick. J Comp Neurol 322:548565.

Husband SA, Shimizu T (1999): Efferent projections of the ectostriatum in the pigeon $(\mathrm{Co}$ lumba livia). J Comp Neurol 406:329-345.

Karten HJ (1967): The ascending auditory pathway in the pigeon (Columba livia). I. Diencephalic projections of the inferior colliculus (nucleus mesencepahlicus lateralis, pars dorsalis). Brain Res 6:409-427.

Karten HJ (1968): The ascending auditory pathway in the pigeon (Columba livia). II. Telencephalic projections of the nucleus ovoidalis thalami. Brain Res 11:134-153.

Karten HJ (1969): The organization of the avian telencephalon and some speculations on the phylogeny of the amniote telencephalon. Ann NY Acad Sci 167:164-179.
Karten HJ (1991): Homology and evolutionary origins of the 'neocortex'. Brain Behav Evol 38:264-272.

Karten HJ (1997): Evolutionary developmental biology meets the brain: the origins of mammalian neocortex. Proc Natl Acad Sci USA 94:2800-2804.

Karten HJ, Hodos W (1970): Telencephalic projections of the nucleus rotundus in the pigeon (Columba livia). J Comp Neurol 140: 35-52.

Karten HJ, Shimizu T (1989): The origins of neocortex: connections and lamination as distinct events in evolution. J Cogn Neurosci 1: 291-301.

Krützfeldt NOE, Wild JM (2004): Definition and connections of the entopallium in the zebra finch (Taeniopygia guttata). J Comp Neurol 468:452-465.

Krützfeldt NOE, Wild JM (2005): Definition and novel connections of the entopallium in the pigeon (Columba livia). J Comp Neurol 490: 40-56.

LeDoux JE, Ruggiero DA, Reis DJ (1985): Projections to the subcortical forebrain from anatomically defined regions of the medial geniculate body in the rat. J Comp Neurol 242: 182-213.

LeDoux JE, Farb C, Reis DJ (1990): Topographic organization of neurons in the acoustic thalamus that project to the amygdale. J Neurosci 1990:1043-1054.

McGeorge AJ, Faull RLM (1989): The organization of the projection from the cerebral cortex to the striatum in the rat. Neuroscience 29:60-92. 
Medina L, Legaz I, Gonzalez G, de Castro F, Rubenstein JLR, Puelles L (2004): Expression of Dbx1, Neuogenin, Semaphorin 5A, Cadherin 8 , and Emx1 distinguish ventral and lateral pallial histogenetic divisions in the developing mouse claustroamygdaloid complex. J Comp Neurol 474:504-523.

- Mello CV, Vates EG, Okuhata S, Nottebohm F (1998): Descending auditory pathways in the adult male zebra finch (Taeniopygia guttata). J Comp Neurol 395:137-160.

Puelles L (2001): Thoughts on the development, structure and evolution of the mammalian and avian telencephalic pallium. Philos Trans R Soc Lond B Biol Sci 356:1583-1598.

Scheich H (1983): Two columnar systems in the auditory neostriatum of the chick: evidence from 2-deoxyglucose. Exp Brain Res 51:199205.

Shimizu T, Karten HJ (1991): Multiple origins of neocortex: contributions of the dorsal ventricular ridge; in Finlay BL, Innocenti G, Scheich H (eds): The Neocortex. New York, Plenum, pp 75-86.
Striedter G (2005): Principles of Brain Evolution. Sunderland, Sinauer.

Vates GE, Broome BM, Mello CV, Nottebohm F (1996): Auditory pathways of caudal telencephalon and their relation to the song system of adult male zebra finches (Taeniopygia guttata). J Comp Neurol 366:613-642.

Veenman CL, Gottschaldt KM (1986): The nucleus basalis-neostriatum complex in the goose (Anser anser L.). Adv Anat Embryol Cell Biol 96:1-85.

Veenman CL, Wild JM, Reiner A (1995): Organization of the avian 'corticostriatal' projection system: a retrograde and anterograde pathway tracing study in pigeons. J Comp Neurol 354:87-126.
-Wang Y, Brzozowska-Prechtl A, Karten HJ (2010): Laminar and columnar auditory cortex in avian brain. Proc Natl Acad Sci USA 107:12676-12681.

Wild JM (1987): The avian somatosensory system: connections of regions of body representation in the forebrain of the pigeon. Brain Res 412:205-223.

Wild JM, Williams MN (2000): Rostral Wulst in passerine birds. I. Origin, course and terminations of an avian 'pyramidal tract'. J Comp Neurol 416:429-450.

Wild JM, Arends JJA, Zeigler HP (1985): Telencephalic connections of the trigeminal system in the pigeon (Columba livia): a trigeminal sensorimotor circuit. J Comp Neurol 234: 441-464.

Wild JM, Karten HJ, Frost BJ (1993): Connections of the auditory forebrain in the pigeon (Columba livia). J Comp Neurol 337:32-62.

Zeier H, Karten HJ (1971): The archistriatum of the pigeon: organization of afferent and efferent connections. Brain Res 31:313-326. 